DIGITALCOMMONS @WAYNESTATE-
Clinical Research in Practice: The Journal of Team Hippocrates

\title{
Myomectomy has better reproductive outcomes than uterine artery embolization for patients with symptomatic leiomyomas who wish maintain fertility
}

Suha Syed

Wayne State University School of Medicine, suha.syed@med.wayne.edu

Follow this and additional works at: https://digitalcommons.wayne.edu/crp

Part of the Medical Education Commons, Obstetrics and Gynecology Commons, and the Translational Medical Research Commons

\section{Recommended Citation}

SYED S. Myomectomy has better reproductive outcomes than uterine artery embolization for patients with symptomatic leiomyomas who wish maintain fertility. Clin. Res. Prac. Oct 16 2020;6(2):eP2286. https://doi.org/10.22237/crp/1593562620

This Clinical Decision Report is brought to you for free and open access by the Open Access Journals at DigitalCommons@WayneState. It has been accepted for inclusion in Clinical Research in Practice: The Journal of Team Hippocrates by an authorized editor of DigitalCommons@WayneState. 


\title{
Myomectomy has better reproductive outcomes than uterine artery embolization for patients with symptomatic leiomyomas who wish maintain fertility
}

SUHA SYED, Wayne State University School of Medicine, suha.syed@med.wayne.edu

\begin{abstract}
A clinical decision report appraising Mara M, Maskova J, Fucikova Z, Kuzel D, Belsan T, Sosna O. Midterm clinical and first reproductive results of a randomized controlled trial comparing uterine fibroid embolization and myomectomy. Cardiovascular and interventional radiology. 2008;31(1):73-85. https://doi.org/10.1007/s00270-007-9195-2
\end{abstract}

Keywords: $\quad$ myomectomy, uterine artery embolization, pregnancy outcomes, symptomatic leiomyomas, leiomyomas, fertility

\section{Clinical Context \\ Diana Johnson (pseudonym), a 36 year-old GOPO African American female with a history of uterine leiomyomas and Crohn's disease, presented to the emergency department with acute worsening of chronic bilateral lower quadrant abdominal pain that radiated to the lower lumbar back. That morning, she awoke to severe "pressure" in her pelvic region with associated lightheadedness, abnormal vaginal bleeding, and urinary frequency. She appeared tearful and acutely distressed on presentation. This patient had been routinely following up with her obstetrics/gynecology clinic since the pain first began three years ago. CT scan had diagnosed an intramural uterine leiomyoma that was approximately $4.3 \mathrm{~cm}$ in size. While in the emergency department, the patient was given IV morphine $4 \mathrm{mg}$ and IV ondansetron $4 \mathrm{mg}$, which helped resolve her pain. She underwent an additional CT scan to rule out perforation or rupture, which were not visualized. As this patient was a GOPO, she talked about her desire for future pregnancy. Knowing a hysterectomy would make this impossible, she asked about potential treatment options that could eliminate her pain without sacrificing her ability to carry a child. She was not interested in hormone therapy but had read about uterine artery embolization and myomectomy. She wondered if either option would jeopardize her fertility. If not, she wanted to know which option was better.}

\section{Clinical Question}

Which treatment option for symptomatic leiomyomas - uterine artery embolization or myomectomy-confers least risk toward future pregnancy?

SUHA SYED is a medical student at Wayne State University School of Medicine. 
SYED S. Myomectomy has better reproductive outcomes than uterine artery embolization for patients with symptomatic leiomyomas who wish maintain fertility. Clin. Res. Prac. Oct 16 2020;6(2):eP2286. https://doi.org/10.22237/crp/1593562620
Clinical Research in Practice The Journal of Team Hippocrates

VOL 6 ISS 2 / eP2286 / OCTOBER 16, 2020 https://doi.org/10.22237/crp/1593562620

\section{Research Article}

Mara M, Maskova J, Fucikova Z, Kuzel D, Belsan T, Sosna O. Midterm clinical and first reproductive results of a randomized controlled trial comparing uterine fibroid embolization and myomectomy. Cardiovascular and interventional radiology. 2008;31(1):73-85. https://doi.org/10.1007/s00270-007-9195-2.

\section{Related Literature}

Information foraging began with an UpToDate search regarding "symptomatic leiomyomas." Non-medical treatment options included hysterectomy, myomectomy, endometrial ablation, myolysis, uterine artery occlusion, and uterine artery embolization. Only myomectomy and uterine artery embolization were suggested for preservation of the uterus for pregnancy. There were two articles referenced for pregnancy results after myomectomy. The first was a case study that discussed a 35-year old woman who had an uncomplicated full term pregnancy after laparoscopic myomectomy..$^{-}$The second was a prospective observational study

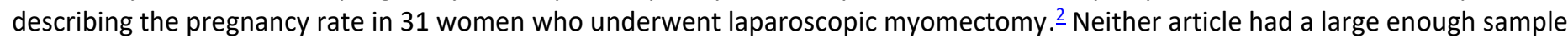
size to be considered for clinical use. In addition, there were no references regarding pregnancy outcomes in patients who had undergone uterine artery embolization.

Further literature review continued with a PubMed search using the keywords "uterine artery embolization," "myomectomy," and "pregnancy[title]." This search returned 8 articles that discussed pregnancy outcomes after treatment of leiomyomas. Six of the articles solely explored pregnancy outcomes after uterine artery embolization. $\frac{3-8}{-8}$ The remaining two manuscripts were reviews that compared uterine artery embolization to myomectomy. $\underline{9,10}$

Firouznia et. al followed 102 patients who underwent uterine artery embolization for symptomatic uterine fibroids, 23 of whom were seeking to become pregnant.. Of the 23,14 became pregnant for a total of 15 pregnancies. There were two miscarriages and 13 full-term elective cesarean deliveries. The limited sample size precludes clinical utility.

Pabon et. al conducted a prospective study at a city hospital in Spain to measure the number and course of pregnancy in 100 patients who had undergone uterine fibroid embolization. $\underline{4}$ Of the 100 patients, only eleven pregnancies were documented in 10 women. There were 3 early miscarriages, 4 vaginal full-term births, and 4 full-term cesarean deliveries. Again, the limited sample size served of lower clinical utility.

Ludwig et al. conducted a review focused on uterine fibroid embolization to compare it to the historically suggested myomectomy. Publications were selected based on relevance of information to fertility and pregnancy without being limited to single case reports. The article had 52 references, of which 7 were randomized controlled trials. I reviewed each one to assess their ability to answer the clinical question. Two of the articles compared uterine artery embolization to hysterectomy, which was not an option for my patient. $.11, \underline{12}$

Ultimately, the article chosen for critical review was a randomized controlled trial conducted by Mara et al. $\frac{13}{\text { Th }}$ The group randomly selected a cohort of 121 patients with symptomatic leiomyomas who desired future pregnancy for either uterine artery embolization or myomectomy. Consistent follow-up with the patients revealed 50 gestations within the following two years. Based on the total number of pregnancies and labors as well as abortion rates, the study concluded that myomectomy has superior reproductive outcomes. In addition, due to the larger sample size, randomized set-up, extended follow-up period, and focus on both symptomatic relief and pregnancy outcomes, I decided to use this study to answer my clinical question.

According to the SORT criteria, it meets Category B Grade of Recommendation based on few lower quality studies. $\underline{14}$

\section{Critical Appraisal}

This research study is a prospective randomized controlled trial comparing symptomatic and reproductive outcomes in uterine artery embolization versus myomectomy in the treatment of uterine fibroids larger than $4 \mathrm{~cm}$. According to the SORT criteria, it meets Level 1 evidence. $\underline{14}$ 
SYED S. Myomectomy has better reproductive outcomes than uterine artery embolization for patients with symptomatic leiomyomas who wish maintain fertility. Clin. Res. Prac. Oct 16 2020;6(2):eP2286. https://doi.org/10.22237/crp/1593562620
Clinical Research in Practice The Journal of Team Hippocrates

VOL 6 ISS 2 / eP2286 / OCTOBER 16, 2020 https://doi.org/10.22237/crp/1593562620

Out of a group of 121 women, 58 received embolization while 63 underwent myomectomy. Their selection for each procedure was randomized by computer-generated code. There was minimal discussion of balance in baseline prognostic variables, so it is possible there were baseline differences between the two randomized groups. Inclusion criteria included (1) ultrasound-verified intramural fibroid of at least $4 \mathrm{~cm},(2)$ age $<40$ years, (3) serum FSH concentration <30 IU/L on the third day of menstrual cycle, and (4) planned pregnancy. $54 \%$ of the group were nulligravid, similar to my patient described above. Prior to the procedures, patients completed a questionnaire defining the intensity of six different myoma-related symptoms, which were compared to opinions afterwards. The subjectivity of these findings is less scientifically sound.

All patients that were assigned to uterine artery embolization were treated by the same interventional radiologist. Trisacryl gelatin microspheres were used for embolization in all cases, and all patients were given the same regiment of pre-embolization antibiotics. All patients that were assigned to the myomectomy arm began with a hysteroscopy. Larger fibroids or unfavorable locations resulted in open myomectomies, while all other cases were performed by laparoscopy. The same two surgeons performed all of the surgeries. The level of training and expertise was not discussed for the interventional radiologist or surgeons. Outcomes could have differed depending on whether they were, for example, early attendings or attendings that had been in practice for decades.

Patients followed up with the research group in 6-month intervals to document history of reproductive attempts. After embolization, $50 \%$ of patients became pregnant, $19 \%$ delivered, and $64 \%$ had a spontaneous abortion. After myomectomy, $78 \%$ of patients became pregnant, $48 \%$ delivered, and $23 \%$ had a spontaneous abortion. The differences were statistically significant.

The study concluded that myomectomy is statistically superior in terms of reproductive outcomes. This was gauged based on the number of successful deliveries and the number of early pregnancy losses. The rate of spontaneous abortions after embolization was greater than $60 \%$ compared to $23 \%$ in the myomectomy group. Both procedures were deemed comparable in respect to technical success, frequency of complications, and relief of symptoms.

The mean age of participants in the study was 32.4 in the embolectomy group and 32.0 in the myomectomy group. The results of the study may be less applicable to my patient, who is 36 years old, however, she still meets the inclusion criteria for the study, which required participants to be younger than 40 . Another limitation is the lack of a control group. The study would benefit from including patients with symptomatic leiomyomas who attempt to become pregnant without any interventions. There was also no discussion of the difference in outcome between the patients who underwent laparoscopic myomectomy versus open myomectomy. These two groups were expressed together despite variances in invasion.

Overall strengths include large sample size, uniformity in procedure, close follow-up with most patients, and the randomized, blinded approach. Each of these individually solidified the outcome as scientifically sound and replicable.

\section{Clinical Application}

Ms. Johnson wanted to know which treatment option for her leiomyoma would be better suited toward her desire to become pregnant. Based on the article presented, I advised her to opt for a myomectomy rather than a uterine artery embolization. The paper also discussed adverse outcomes of the procedures, of which all were relatively mild and transient. Myomectomy appears to be a safe solution to treating Ms. Johnson's symptoms without jeopardizing her parity. However, it is also important that she regularly follow up with her physician to monitor for recurrence of the leiomyoma and to ensure a healthy gestation if she does become pregnant.

\section{New Knowledge Related to Clinical Decision Science}

Ms. Johnson's concerns about the removal of her leiomyoma while maintaining her fertility led the treatment team to investigate which treatment would be recommended for her. As she initially presented both myomectomy and uterine artery embolization as options, these were the driving factors in our discussion and evidence search. If Ms. Johnson did not speak up, she might have received hormone therapy, or another methodology that she would not have been happy with. Instead, we were able to speak about the patient's question and fear of permanent nulliparity. This clinical decision was driven by the severity of Ms. Johnson's symptoms and her preferences. Often doctors need evidence to support the patient's preferences. If there is documented danger, 
SYED S. Myomectomy has better reproductive outcomes than uterine artery embolization for patients with symptomatic leiomyomas who wish maintain fertility. Clin. Res. Prac. Oct 16 2020;6(2):eP2286. https://doi.org/10.22237/crp/1593562620
Clinical Research in Practice The Journal of Team Hippocrates

VOL 6 ISS 2 / eP2286 / OCTOBER 16, 2020 https://doi.org/10.22237/crp/1593562620

we are obligated to share that as well with our patients. The strength of our reassurance or caution is a blend of clinical evidence and understanding the patient.

\section{References}

1. Bocca S, Stadtmauer L, Oehninger S. Uncomplicated full term pregnancy after da Vinci-assisted laparoscopic myomectomy. Reproductive biomedicine online. 2007;14(2):246-249. https://doi.org/10.1016/s1472-6483(10)60794-8

2. Lönnerfors C, Persson J. Pregnancy following robot-assisted laparoscopic myomectomy in women with deep intramural myomas. Acta obstetricia et gynecologica Scandinavica. 2011;90(9):972-977. https://doi.org/10.1111/i.1600-0412.2011.012207.x

3. Firouznia K, Ghanaati H, Sanaati M, Jalali AH, Shakiba M. Pregnancy after uterine artery embolization for symptomatic fibroids: a series of 15 pregnancies. American Journal of Roentgenology. 2009;192(6):1588-1592. https://doi.org/10.2214/ajr.07.3904

4. Pabón IP, Magret JP, Unzurrunzaga EA, García IM, Catalán IB, Vieco MLC. Pregnancy after uterine fibroid embolization: follow-up of 100 patients embolized using tris-acryl gelatin microspheres. Fertility and sterility. 2008;90(6):2356-2360. https://doi.org/10.1016/i.fertnstert.2007.10.074

5. Ludwig PE, Huff TJ, Shanahan MM, Stavas JM. Pregnancy success and outcomes after uterine fibroid embolization: updated review of published literature. The British Journal of Radiology. 2020;93(1105):20190551. https://doi.org/10.1259/bjr.20190551

6. Usadi RS, Marshburn PB. The impact of uterine artery embolization on fertility and pregnancy outcome. Current opinion in obstetrics and gynecology. 2007;19(3):279-283. https://doi.org/10.1097/gco.0b013e3281099659

7. Nabeshima H, Murakami T, Sato Y, Terada Y, Yaegashi N, Okamura K. Successful pregnancy after myomectomy using preoperative adjuvant uterine artery embolization. The Tohoku journal of experimental medicine. 2003;200(3):145-149. https://doi.org/10.1620/tjem.200.145

8. Goldberg J, Pereira L, Berghella V. Pregnancy after uterine artery embolization. Obstetrics \& Gynecology. 2002;100(5):869-872. https://doi.org/10.1097/00006250-200211000-00006

9. Goldberg J, Pereira L. Pregnancy outcomes following treatment for fibroids: uterine fibroid embolization versus laparoscopic myomectomy. Current Opinion in Obstetrics and Gynecology. 2006;18(4):402-406. https://doi.org/10.1097/01.gco.0000233934.13684.cb

10. Goldberg J, Pereira L, Berghella V, Diamond J, Daraï E, Seinera P, Seracchioli R. Pregnancy outcomes after treatment for fibromyomata: uterine artery embolization versus laparoscopic myomectomy. American journal of obstetrics and gynecology. 2004;191(1):18-21. https://doi.org/10.1016/i.ajog.2004.01.046

11. Pinto I, Chimeno P, Romo A, Paúl L, Haya J, de la Cal MA, Bajo J. Uterine fibroids: uterine artery embolization versus abdominal hysterectomy for treatment-a prospective, randomized, and controlled clinical trial. Radiology. 2003;226(2):425-431. https://doi.org/10.1148/radiol.2262011716

12. Hehenkamp WJ, Volkers NA, Donderwinkel PF, de Blok S, Birnie E, Ankum WM, Reekers JA. Uterine artery embolization versus hysterectomy in the treatment of symptomatic uterine fibroids (EMMY trial): peri-and postprocedural results from a randomized controlled trial. American journal of obstetrics and gynecology. 2005;193(5):1618-1629. https://doi.org/10.1016/j.ajog.2005.05.017

13. Mara M, Maskova J, Fucikova Z, Kuzel D, Belsan T, Sosna O. Midterm clinical and first reproductive results of a randomized controlled trial comparing uterine fibroid embolization and myomectomy. Cardiovascular and interventional radiology. 2008;31(1):73-85. https://doi.org/10.1007/s00270-007-9195-2

14. Ebell MH, Siwek J, Weiss BD, et al. Strength of Recommendation Taxonomy (SORT): a patient-centered approach to grading evidence in the medical literature. J Am Board Fam Med. 2004;17(1):59-67. https://doi.org/10.3122/jabfm.17.1.59 